\title{
«YO TAMBIÉN OS DIGO Á LAS ARMAS». COMANDANTES DE LA GUARDIA NACIONAL Y CAUDILLOS MITRISTAS EN LA REVOLUCIÓN DE 1874 (PROVINCIA DE BUENOS AIRES, ARGENTINA) \\ "Yo también os digo á las armas". National Guard commandants and mitristas caudillos in the Revolution of 1874 (Buenos Aires province, Argentina)
}

\author{
LEONARDO CANCIANI \\ Universidad Nacional del Centro de la Provincia de Buenos Aires \\ Consejo Nacional de Investigaciones Científicas y Técnicas \\ Icanciani@fch.unicen.edu.ar
}

Cómo citar/Citation

Canciani, L. (2017)

"Yo también os digo á las armas». Comandantes de la Guardia Nacional y caudillos mitristas en la Revolución de 1874 (provincia de Buenos Aires, Argentina). Historia y Política, 37, 211-240 doi: https://doi.org/10.18042/hp.37.08

\section{Resumen}

En este artículo, estudiamos la participación que tuvieron en la revolución mitrista de 1874 los comandantes de la Guardia Nacional y los jefes militares-milicianos rebeldes de la provincia de Buenos Aires. Primero, examinamos los días iniciales de la revolución y reconstruimos el rol de las autoridades locales leales al gobierno y de los comandantes rebeldes que llevaron adelante este movimiento en la campaña. Segundo, analizamos los mecanismos de reclutamiento que implementó el coronel Benito Machado para reunir guardias nacionales y sumar recursos a la causa mitrista. Argumentamos que, si bien la victoria del gobierno representó una mayor consolidación para el Estado nacional argentino, la movilización armada que 
lograron los comandantes rebeldes y los caudillos mitristas evidencia su capacidad de resistencia a la pérdida del poder que aún mantenían en el sur y en la frontera de la provincia de Buenos Aires.

\section{Palabras clave}

Revolución de 1874; Buenos Aires; comandantes de la Guardia Nacional; caudillos; Benito Machado.

\section{Abstract}

In this paper we will analyze the participation of the commanders of the National Guard and the military-militia leaders of the province Buenos Aires in the revolution mitrista (1874). First, we examine the initial days of the revolution and reconstructions the role of the local authorities loyal to the government and the rebel commandants who carried out this movement in the campaign. Second, we study the recruitment mechanisms that implement the Colonel Benito Machado for gather National Guard and add resources to the cause mitrista. The victory of the government represents further consolidation for Argentine National State. We conclude that, the armed mobilization that accomplished the rebel commandants and the caudillos mitristas demonstrates its resilience to the loss of power that still maintain in the south and in the frontier of Buenos Aires province.

\section{Keywords}

Revolution of 1874; Buenos Aires; National Guard commandants; caudillos; Benito Machado. 


\section{SUMARIO}

I. INTRODUCCIÓN. II. GUARDIA NACIONAL, COMANDANTES Y REVOLUCIÓN. III. AUTORIDADES LEALES VERSUS COMANDANTES REBELDES: LA DISPUTA POR HOMBRES Y RECURSOS. IV. BENITO MACHADO Y EL REGIMIENTO SOL DE MAYO: VÍNCULOS Y LEALTADES EN LA REVOLUCIÓN. V. CONSIDERACIONES FINALES. BIBLIOGRAFIA.

\section{INTRODUCCIÓN}

Hacia fines de 1873, la disputa por la sucesión presidencial de Domingo Sarmiento (1868-1874) copó la escena política argentina. El 1 de febrero del año siguiente se llevaron a cabo los comicios para la renovación de las cámaras legislativas nacionales, con resultados contundentes a favor de los candidatos de Nicolás Avellaneda, que triunfaron en diez de las catorce provincias. En cambio, en Buenos Aires fueron controvertidos. Si bien, la junta electoral le dio la victoria a la lista que patrocinaba Adolfo Alsina, generó denuncias de "fraude» desde sus oponentes, los sectores mitristas. En este contexto, se realinearon las candidaturas presidenciales. Alsina declinó su posición y sumó el apoyo de los autonomistas a Avellaneda, quien derrotó a Mitre en las urnas de todo el país, el 12 de abril, obteniendo 146 electores frente a los 79 de su rival.

El nuevo presidente asumió el cargo el 12 de octubre de 1874 en un clima político y militar convulsionado. El 24 de septiembre, los mitristas y sus aliados se levantaron en armas. El movimiento tuvo tres focos principales: Montevideo, sede del comité revolucionario; la frontera sur de Córdoba, San Luis y Cuyo, al mando del general José Arredondo; y el sur y la frontera de la provincia de Buenos Aires, a cargo del general Ignacio Rivas y, luego, del propio Mitre. Pese a los apoyos que suscitó, la revolución fue duramente reprimida por las fuerzas del Estado nacional. La derrota de los mitristas en los combates de La Verde (provincia de Buenos Aires) y Santa Rosa (provincia de Mendoza) frustró el alzamiento y pusieron fin a sus propósitos.

Hasta hace algunos años, este conflicto militar no había recibido mucha atención de parte de la historiografía argentina. Disponíamos de enumeraciones de los principales hechos del levantamiento ${ }^{1}$, que han sido revitalizadas en trabajos recientes y reediciones que se concentran en los episodios militares y

$1 \quad$ Saldías (1910) y Rosa (1977). 
en la transcripción de documentación referente a ese acontecimiento ${ }^{2}$. Posteriormente, aparecieron investigaciones que analizaban dicha revolución enmarcada en un contexto mayor, que definieron como «organización nacional $»^{3}$ o «treinta años de discordia»", y en la cultura política revolucionaria decimonónica ${ }^{5}$. Finalmente, disponemos de bibliografía para la campaña y la frontera de Buenos Aires ${ }^{6}$, para los sucesos que se desarrollaron en las provincias de Córdoba, San Luis y la región de Cuyo y para sus efectos en el norte del país?

La renovación de la historia política que se produjo en los países de América Latina desde la década de 1980 dio lugar a preguntas y métodos de investigación novedosos. A partir de entonces, se alejó de la historia fáctica, de los hechos, de las biografías políticas y de la dimensión conmemorativa ${ }^{8}$ y se volcó en el poder político y su ejercicio y en la participación de los grupos sociales en las elecciones, los partidos políticos, el Estado y sus instituciones?. En la historiografía argentina, la construcción del Estado y la Nación se tomaron como problemas y se interrogaron los complejos procesos políticos que tuvieron lugar luego de las guerras de independencia. Se estudiaron los diferentes proyectos, intentos y ensayos de formación de las nuevas comunidades políticas, así como las variantes que se abrieron una vez instituida la república, que alimentaron los conflictos de la segunda mitad del siglo XIX. En lo que respecta al terreno de las prácticas políticas, se profundizó el estudio de la participación electoral, los comicios, las redes políticas y las clientelas; la estructura y actividad de las milicias y la Guardia Nacional; las formas de acción, las revoluciones y las movilizaciones colectivas de la población, entre otros temas ${ }^{10}$.

En el marco de esta renovación, la revolución de 1874 fue interpretada como uno de los tantos casos de "violencia política» que caracterizaron el siglo XIX en América Latina. De acuerdo con Irurozqui, por ella se entiende a «los hechos de fuerza con intencionalidad pública que convocan a un grupo de

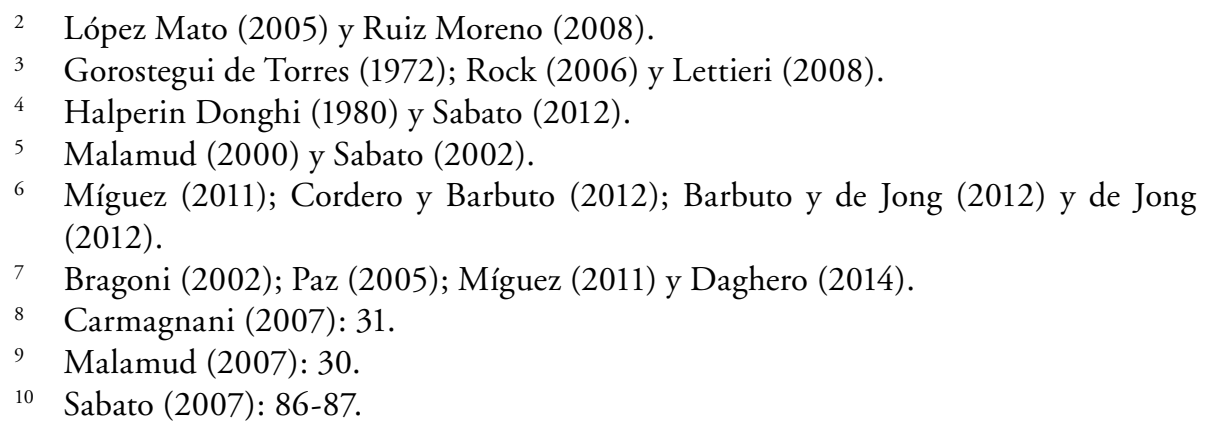


individuos en torno a instancias, demandas, cuestionamientos o aspiraciones de poder». Por entonces, el Estado nacional no era el único ámbito soberano de decisión y supremo de poder, ya que aún no había monopolizado el empleo de las armas en el territorio que consideraba de su dominio y, por el contrario, así como los militares podían ocupar puestos de gobierno, los civiles podían promover, organizar y liderar pronunciamientos armados. Estas acciones formaban parte del repertorio político de la cultura constitucional de la época y, por lo tanto, constituyen una variable fundamental para explicar la formación de los Estados nacionales ${ }^{11}$. La guerra tuvo un papel de primera importancia en el proceso de construcción estatal, especialmente en su búsqueda ineludible de monopolizar los medios de coerción ${ }^{12}$. En este sentido, Pro Ruiz sostiene que su significado no es inequívoco y que, por lo tanto, depende del contexto político, económico y social en el que se produzca, y del tipo de guerra que se desarrolle. Si bien en ocasiones contribuyó a la eliminación de actores que hasta entonces habían gozado de cierta autonomía, allanando el camino para la centralización estatal y la consiguiente construcción del Estado nacional, en otras produjo el resultado exactamente contrario al demostrar la capacidad de resistencia de algunos poderes locales y/o territoriales insumisos a la lógica estatista que se intentaba consolidar desde los sectores dirigentes ${ }^{13}$.

Por lo general, estos actores han sido definidos despectivamente con el rótulo de caudillos. El poder de estos actores ha dejado de verse como una aberración histórica y pasó a considerarse como un proceso social y político de construcción del poder en coyunturas históricas particulares. Hoy sabemos que estos líderes políticos y militares locales, que solían defender la autonomía provincial, no sostuvieron su poder en un "vacío institucional» y mediante mecanismos de dominio y de control exclusivamente coercitivos, sino en el marco de una serie de normas que fueron sancionando los distintos Estados provinciales y, a su vez, avalados por el apoyo popular de sus seguidores, que en muchas ocasiones se expresaba a través de las urnas ${ }^{14}$. Según se ha sostenido, desde mediados del siglo XIX, los caudillos de la frontera bonaerense se vieron afectados por la tensión que se generó entre el proyecto reformista del Estado liberal y las prácticas políticas de construcción del poder en la frontera. Por ese entonces, este territorio fuertemente militarizado aún se mantenía ajeno al control directo del Estado nacional, que exigía la subordinación de los caudillos locales a un entramado de fuerzas más centralizado. Para ello,

11 Irurozqui (2015): 197-200.

12 Tilly (1992): 121; Oszlak (2009) [1982]: 275 y Garavaglia (2012): 13.

13 Pro Ruiz (2012): 29.

14 Goldman y Salvatore (2005); Rock (2006); de la Fuente (2007) y Lanteri (2011). 
estos últimos debieron renunciar a parte de su autonomía y adaptarse a reglas de juego diferentes. No obstante, este proceso no se desarrolló de forma pacífica. Los que no se vieron favorecidos, o no pudieron adaptarse a la nueva relación propuesta por el Estado, vieron peligrar su lugar hegemónico, dando lugar a rebeliones y represiones ${ }^{15}$. La revolución de 1874 fue una de estas expresiones.

En concordancia con los planteamientos que presentamos, nos interesa examinar los resultados del levantamiento mitrista que, en general, no han sido muy abordados por la historiografía. En especial, el impacto que tuvo esta frustrada revolución en los caudillos mitristas de la campaña y la frontera de Buenos Aires que fueron derrotados. Argumentaremos que, si bien tuvo una serie de consecuencias para el Estado nacional en proceso de construcción y para sus gobernantes, también evidenció algunas cuestiones ligadas al poder que tuvieron aquellos y de qué forma sus acciones tuvieron implicaciones en su liderazgo y en el mismo Estado que les disputaba ese poder. Por un lado, examinaremos el rol que desempañaron en los primeros momentos de la revolución las autoridades locales leales al Gobierno provincial autonomista y los jefes rebeldes que llevaron adelante el movimiento en la campaña y la frontera. Por otro lado, reconstruiremos los mecanismos de reclutamiento que implementaron los caudillos territoriales mitristas, con el fin de reunir la mayor cantidad posible de guardias nacionales para la revolución, concentrándonos en el caso del coronel Benito Machado.

Antes de abocarnos en esta tarea, expondremos a modo aclaratorio las principales características institucionales de la Guardia Nacional, así como su participación en el ámbito político y militar, y repasamos algunos aspectos esenciales de la revolución.

\section{GUARDIA NACIONAL, COMANDANTES Y REVOLUCIÓN}

Como han planteado Macías y Sabato, la Guardia Nacional se convirtió en el núcleo de una discusión historiográfica que busca responder algunos interrogantes generados en torno al problema de la centralización del poder militar del Estado y de la construcción de un «orden» político en la Argentina decimonónica ${ }^{16}$. En la provincia de Buenos Aires, se creó el 8 de marzo de 1852 , ante «la necesidad urgente de dar para el porvenir una custodia fiel y firme al tesoro precioso de las Leyes, y también un apoyo fuerte á la autoridad

15 Míguez (2010): 81 y 97.

16 Macías y Sabato (2013): 71-72. 
legítimamente constituida $»^{17}$. De igual modo, el Gobierno de la Confederación Argentina decretó su establecimiento dos años después, para garantizar «la defensa de la patria y de sus instituciones» $\mathrm{y}$ «afianzar el órden, las leyes, las garantías del ciudadano y los benéficos resultados que debe producir un esfuerzo común y Nacional» ${ }^{18}$.

La Guardia Nacional constituía una suerte de milicia nacional que tuvo como objetivo formar una reserva para el Ejército de Línea. Sin embargo, representaban dos modelos diferentes de organización militar y de entender el poder de coerción del Estado, ya que aquella contrapesaba el sentido de defensa centralizado que acuñaba este último. Mientras que la Guardia Nacional estaba integrada por todos los ciudadanos argentinos mayores de edad (dieciocho a sesenta años) con domicilio en la ciudad o la campaña, que tuvieran pleno goce de sus derechos civiles y políticos, el Ejército regular nutría sus filas de soldados a sueldo que se habían incorporado de forma voluntaria o habían sido obligados a hacerlo, como así también de criminales que cumplían allí su condena. Se edificó sobre la base de un imaginario cívico patriótico sostenido en la figura del ciudadano armado. Estar enrolado no conllevaba a un servicio permanente, sino a la obligación de estar dispuesto y preparado para empuñar las armas cuando fuese convocado por las autoridades provinciales y nacionales ${ }^{19}$.

La Guardia Nacional tuvo un papel importante en la defensa de la frontera con los indígenas. En la provincia de Buenos Aires, la movilización ordinaria de contingentes y de guardias nacionales de forma momentánea para ser licenciados en días o semanas fue algo recurrente en la historia de los regimientos de campaña. Actuó en ese territorio en refuerzo del Ejército de Línea, debido a que la falta de soldados regulares fue un problema permanente durante el período 1852-1878. El servicio miliciano en la frontera fue un ámbito propicio para que los comandantes construyeran sólidos liderazgos políticos, a partir del lugar destacado que tuvieron en los regimientos.

Al mismo tiempo, participó en las elecciones y las revoluciones que se produjeron en la segunda mitad del siglo XIX. Como ha planteado Macías, se convirtió en un componente político peligroso, en la medida en que no respondía íntegramente a las decisiones del gobernador ${ }^{20}$. Los comandantes participaban de los sufragios poniendo en práctica diversos instrumentos, con el fin de obtener resultados beneficiosos para su agrupación política, por lo cual

\footnotetext{
Registro Oficial del Gobierno de Buenos Aires (1852): 39.

Registro Oficial de la República Argentina, tomo III (1882): 109.

Sabato (2008): 49-52 y Macías (2014): 93-95.

20 Macías (2014): 129.
} 
fueron una verdadera «máquina electoral». A partir de la ley de 1863 —que rigió hasta 1877—, para poder ejercer su derecho a elegir, los ciudadanos debían estar enrolados en los respectivos regimientos y portar el día de la votación la correspondiente papeleta que lo certificara. Este requisito daba a los comandantes el poder de controlar, falsificar y suprimir boletas, lo que los convertía en personajes claves en las elecciones ${ }^{21}$. Por otro lado, los comandantes movilizaron grandes contingentes de hombres para engrosar las fuerzas revolucionarias, apelando a mecanismos coercitivos y activando los vínculos que habían construido en las fuerzas que estuvieron bajo su mando. La revolución remitía al derecho a la resistencia frente al despotismo y se vinculaba con la figura de la «ciudadanía armada». Cuando los gobernantes abusaban del poder, el pueblo tenía el deber cívico de hacer uso de la fuerza para restaurar las libertades perdidas y el orden presumiblemente violado por el déspota ${ }^{22}$. Con la sanción de la Constitución en 1853, las revoluciones se efectuaron en el marco de argumentaciones basadas en la Carta Magna y en los principios fundacionales de la Guardia Nacional, edificada sobre los preceptos de la «ciudadanía armada $»^{23}$.

La revolución de 1874 no se produjo contra el Gobierno de Sarmiento, sino en respuesta a una derrota electoral que los mitristas consideraban había sido producto del fraude y de la utilización de recursos a disposición de la alianza oficialista que patrocinaba la candidatura de Avellaneda. Los mitristas acusaban a sus rivales de haber fraguado los resultados de las elecciones legislativas que se desarrollaron el 1 de febrero de ese año en Buenos Aires. Según ellos, el rotundo triunfo de sus listas en los comicios presidenciales de abril confirmaba que la provincia les favorecía y demostraba que los resultados anteriores habían sido falseados. Cuando finalmente estos fueron confirmados, los partidarios de Mitre decidieron que era el momento de levantarse en armas y hacer una revolución. Si bien el proceso electoral en esos años implicaba la utilización de mecanismos de presión y manipulación por parte de los contendientes, los derrotados no perdían la oportunidad de denunciar a los ganadores por fraude. Cuando estos pertenecían al partido oficial, se habría la brecha para la impugnación revolucionaria, como ocurrió en $1874^{24}$.

Los argumentos que Mitre expuso al desembarcar en la costa bonaerense, con los cuales buscaba justificar la revolución y estimular a sus seguidores, apuntaban a restaurar la Constitución Nacional y las libertades individuales.

\footnotetext{
Heras (1954): 70 y Sabato (1998): 140.

Sabato (2008): 183-185.

Macías (2014): 225.

4 Sabato (2012): 227.
} 
En la proclama que lanzó a sus «compatriotas y compañeros de armas», hablaba de que la «revolución es un derecho contra la violencia», «un deber del patriotismo», «una necesidad imperiosa para salvar la asociación política amenazada por la corrupción oficial» y de «salvar nuestra dignidad de pueblo libre que se hallaba comprometida». Se levantaban contra los «mandatarios infieles que pretenden imponerse por el fraude y la violencia [...] sin conciencia para despojar á los ciudadanos [...] del derecho de sufragar libremente». En tanto «defensores de la ley constitucional violada» sostenía que «nuestra causa tiene la sanción de la justicia, y está autorizada por la ley constitucional, cuya verdad invocamos $\aleph^{25}$. Por lo tanto, con esta recurrente referencia a la Carta Magna, no debe extrañarnos que la fuerza mitrista se autodenominara Ejército Constitucional.

Sin embargo, para los Gobiernos nacional y provincial la revolución tenía otras características. El gobernador de Buenos Aires, Álvaro Barros, sostenía que representaba un "atentado inaudito" e «insensato motín de algunos malos ciudadanos» que querían dar «un golpe contra las autoridades constituidas». Por su parte, Domingo Sarmiento la definió como «una conspiración que se proponía rectificar el voto de pueblo, aprobado, sancionado y proclamado por la ley». Finalmente, durante la asunción presidencial, Nicolás Avellaneda planteó que los éxitos parciales de las fuerzas nacionales constituían «la victoria cívica de los pueblos contra un motín de cuartel». Para el nuevo mandatario, la revolución mitrista no era más que una «revuelta», un «episodio criminal» que enfrentaba las instituciones y los principios republicanos, "la última conjuración de una fracción oligárquica [...] que quería levantar su orgullo ó su demencia sobre el voto de los pueblos $»^{26}$.

Más allá de estos conceptos retóricos, Lettieri planteó que el alzamiento revolucionario representó el "último recurso» de los mitristas para evitar la catástrofe política que se había iniciado años atrás. Al final de su Gobierno, Mitre no había podido imponer a su sucesor en las elecciones de 1868 y tampoco mantener una preeminencia institucional en Buenos Aires más allá de 1866, año en que el autonomismo accedió a la gobernación, para luego conservarla por más de una década. En 1874, los resultados comiciales lo colocaron en una situación institucional crítica, ya que la derrota nacional y provincial acababa con sus aspiraciones presidenciales y condenaba a su partido a una endémica representación en las cámaras legislativas nacionales ${ }^{27}$.

25 Del Mármol (1876): 149-150.

26 Del Mármol (1876): 522, 653 y 580.

27 Lettieri (2008): 66. 
Según sostiene Míguez, se convirtió en «la eterna eminencia en la oposición». Si bien su relación con los Gobiernos de turno varió mucho en diferentes etapas y ciertos dirigentes mitristas ocuparon puestos relevantes en el Gobierno, como ministerios, nunca más volvió a conquistar el poder, ni a formar parte del estrecho elenco del Ejecutivo Nacional. En cambio siempre fue frustrado candidato a volver a la presidencia del país ${ }^{28}$.

\section{AUTORIDADES LEALES VERSUS COMANDANTES REBELDES: LA DISPUTA POR HOMBRES Y RECURSOS}

El 24 de septiembre de 1874, día en que se inició la revolución, el Congreso de la Nación se reunió para tratar la situación y declaró el estado de sitio en las provincias de Buenos Aires, Santa Fe, Entre Ríos y Corrientes, al tiempo que autorizaron al presidente para movilizar las milicias de todo el país. Por su parte, el gobernador de Buenos Aires Álvaro Barros decretó la reunión de la Guardia Nacional de toda la provincia y la llamó «á sostener y hacer efectivas las conquistas de la libertad y del orden $»^{29}$. En los días siguientes, aparecieron en la prensa las órdenes de reunión de los distintos batallones de guardias nacionales, para lo cual se indicaban los lugares y momentos de presentación. Una vez derrotada la revolución, el flamante ministro de Guerra y Marina de la Nación, Adolfo Alsina, afirmaría con gran entusiasmo que «la actitud de la Guardia Nacional en toda la República, ha[bía] ofrecido un espectáculo imponente», debido a «la prontitud con que acudió al llamado del Gobierno, la organización rápida que recibió, la bravura con que luchó toda vez que la ocasión se presentara» ${ }^{30}$. En esta afirmación, no consideraba el rol de los guardias nacionales que, por diversos motivos, se habían plegado a las filas mitristas en el levantamiento, sobre todo en la frontera sur del país.

Los comandantes de los batallones de la ciudad de Buenos Aires no prescindieron de utilizar mecanismos inapropiados con el propósito de formar los cuerpos milicianos. Para evitar ese tipo de prácticas, el Ministerio de Gobierno emitió una circular dirigida a los jefes de la Guardia Nacional movilizada de la capital en la cual ordenaba a las comisiones que recorrían la ciudad que se abstuvieran de llevar a los cuarteles a los extranjeros. La percepción de estos últimos es indicativa de lo reiterado de estas prácticas, ya que, una vez

\footnotetext{
Míguez (2011): 105.

Del Mármol (1876): 522.

30 Memoria del Ministerio de Guerra y Marina de la Nación (1875): 14.
} 
conocida la noticia del reclutamiento, concurrieron masivamente a los consulados en busca de la papeleta de nacionalidad, llegando a producirse tumultos ${ }^{31}$.

Además de estos mecanismos compulsivos de reclutamiento, algunos ciudadanos porteños se presentaron voluntariamente al Gobierno provincial. El 25 de septiembre, más de una veintena de ciudadanos se ofrecieron a «contribuir por cuantos medios estén á sus alcances á efecto de organizar la acción del gobierno contra la criminal rebelión ${ }^{32}$. Por su parte, el 11 de octubre, Luis María Gonnet, «en nombre de un número crecido de estudiantes [...] exonerados del servicio", se presentó al gobernador para informarle que los firmantes habían decidido formar un regimiento de voluntarios de mil plazas destinado a la defensa de la capital en caso de que ello fuera necesario ${ }^{33}$. En otras ocasiones, los que ofrecieron sus servicios al Gobierno fueron algunos jefes militares y oficiales retirados del Ejército, los funcionarios públicos y, hasta incluso, algunos presos, que buscaban obtener la reducción o eliminación de su pena en reconocimiento de su "patriotismo»"

En la campaña y la frontera bonaerense, el reclutamiento de las fuerzas rebeldes se llevó a cabo a través de diversas estrategias. A pocos días de que debiera dejar la presidencia de la Nación, Sarmiento advertía a la población:

D. Bartolomé Mitre no puede mandaros porque ha pedido su baja, y desnudádose de los privilegios de su mando. Es traidor el que le obedece voluntariamente, no teniendo aquel título ni comisión para ejercer mando. Rivas, Obligado y Arredondo no pueden mandaros porque no tienen comisión de gobierno alguno, ni aun de un gobierno revolucionario, que no existe ${ }^{35}$.

Sin embargo, pese a esta advertencia, las fuerzas militares y milicianas respondían a un jefe particular, «a uno de carne y hueso con nombre y apellido», más a que a la autoridad de un superior que había sido investido por el Gobierno o las ordenanzas militares ${ }^{36}$. Los jefes del Ejército de Línea pudieron disponer de los regimientos de caballería y de los batallones de infantería que estaban acantonados en la frontera. Por entonces, Francisco Borges estaba a cargo de la Comandancia General de las fronteras Sud de Santa Fe y Norte

31 Cordero y Barbuto (2012): 159.

32 Archivo Histórico de la Provincia de Buenos Aires [AHPBA], Ministerio de Gobierno, año 1874, leg. 21, exp. 843, fs. 51-52.

33 AHPBA, Inspección General de Milicias, leg. 49, exp. 469.

34 AHPBA, Ministerio de Gobierno, año 1874, leg. 20, exp. 842, fs. 36, 45, 305 y 352.

35 Del Mármol (1876): 567.

36 Míguez (2003): 32. 
y Oeste de Buenos Aires, Ignacio Rivas de la Comandancia General de las fronteras Sud, Costa Sud y Bahía Blanca y Julián Murga de la Comandancia Militar de Patagones. El comportamiento que siguieron estos jefes militares fue diferente. Si bien Borges se plegó a la revolución, lo hizo en soledad, luego de entregar a su subalterno, Hilario Lagos, el mando de los cuerpos a su cargo, restando a la revolución entre seiscientos y ochocientos hombres bien armados y disciplinados con los que Mitre y Rivas contaban. Este último, por su parte, pudo disponer de los cuerpos que estaban bajo el mando de jefes leales, como José María Morales, Julián Murga, Nicolás Ocampo, Ignacio Segovia y Francisco Leyría ${ }^{37}$. Por un breve momento, el Ejército Constitucional también contó con el apoyo de mil quinientos lanceros de «indios amigos» de Cipriano Catriel, aunque no participación en los enfrentamientos ${ }^{38}$.

Además de las tropas regulares, una parte considerable del ejército mitrista estuvo constituido por fuerzas milicianas al mando de líderes locales. En la campaña bonaerense, el primer problema con que se toparon los jefes revolucionarios fue la hostilidad de las autoridades civiles y milicianas. Debido a que los jueces de paz y los comandantes de la Guardia Nacional eran nombrados por el gobernador, al integrar este último el autonomismo, una parte importante de las autoridades de la campaña respondían a esa agrupación política o, en su defecto, abrazaban la neutralidad; aunque, no podemos afirmar que las autoridades locales siguieron de forma indiscutida las directrices que se impartían de la ciudad de Buenos Aires, ya que podían volcar sus esfuerzos en la dirección contraria al gobernador ${ }^{39}$.

La importancia que tuvieron las autoridades locales para defender al Gobierno se puede ver a través de algunos ejemplos. En el norte de la provincia de Buenos Aires y la campaña más cercana a la ciudad capital, el apoyo de aquellas fue mayoritario. El mismo día que estallaba la revolución, el juez de paz de Lomas de Zamora reportaba su predisposición para «segundar las miras de la autoridad Superior, á fin de mantener el orden público» ${ }^{40}$. Desde Conchas, el comandante militar informaba que había reunido la Guardia Nacional del partido y con ella marchado a San Fernando, con el propósito de preservar la autoridad del juez de paz y reducir a los grupos mitristas, a los cuales se les arrebató cuatro carros de equipamiento militar, recados y fusiles. A su vez, solicitaba armamento y un oficial de Línea subalterno para que lo escoltase

37 Ruiz Moreno (2008) y Teófilo Gomila, «La revolución de 1874». De Jong y Satas (2011).

38 De Jong (2012).

39 Canciani (2015): 61.

40 AHPBA, Ministerio de Gobierno, año 1874, leg. 21, exp. 843, f. 1. 
en la organización de la fuerza miliciana ${ }^{41}$. Al día siguiente, el juez de paz de Belgrano comunicaba que «se adoptaron varias medidas para la conservación del orden y [en] apoyo de las autoridades». Para ello, el comandante de la Guardia Nacional había reunido cien hombres y caballos suficientes, aunque solicitaba el envío de armas y monturas ${ }^{42}$. En San Isidro, el juez de paz había ordenado la movilización de los guardias nacionales de ese distrito, para que reconocieran al nuevo comandante, y reemplazado a los alcaldes de los cuarteles 2, 3 y 8, para favorecer «el mejor servicio público» ${ }^{43}$. Desde Merlo, el comandante militar informaba que «la Guardia Nacional se reun[ía] con entusiasmo en defensa de la constitución y de las leyes» y solicitaba armamentos y municiones $^{44}$. Su par de Lobos había suspendido a la mitad de los capitanes de las compañías de ese partido, a causa de que los consideraba «manifiestos opositores al gobierno", y pedía que se lo autorizara para nombrar a nuevos vecinos en esos puestos. Para evitar cualquier inconveniente, que derivara en la sublevación de parte de la Guardia Nacional, había decidido no reunir esa fuerza como había sido ordenado por el gobernador ${ }^{45}$. Por su parte, el comandante de la Guardia Nacional de Castelli mostraba su lealtad al gobernador, al afirmar que "la gente está dispuesta há sostener el orden», y le solicitaba armas, pues solo contaba con doce sables y seis tercerolas, que creía insuficientes hacer frente a un movimiento rebelde en su distrito ${ }^{46}$. El 28 de septiembre, el comandante interino de la Guardia Nacional de Ranchos reportaba que había enviado una partida de ochenta guardias nacionales y un piquete de veinticinco tiradores al partido de Monte, donde se estaban reuniendo grupos de mitristas armados, con el objetivo de reducirlos ${ }^{47}$. El 1 de octubre, el juez de paz de Ramallo informaba al ministro de Gobierno que ese partido estaba tranquilo y que los vecinos se presentaban con gran entusiasmo a servir «en favor de la causa del orden y de las instituciones» y que ninguno se había resistido a su llamado para hacer servicio activo de policía ${ }^{48}$. Un día después, desde Pergamino, el juez de paz informaba que la reunión de la Guardia Nacional se encontraba «muy adelantada», así como la expropiación de caballos para garantizar su montura ${ }^{49}$.

\footnotetext{
AHPBA, Ministerio de Gobierno, año 1874, leg. 21, exp. 843, fs. 40-41.

AHPBA, Ministerio de Gobierno, año 1874, leg. 21, exp. 843, fs. 13 y 42.

AHPBA, Ministerio de Gobierno, año 1874, leg. 21, exp. 843, fs. 18 y 64.

AHPBA, Ministerio de Gobierno, año 1874, leg. 21, exp. 843.

AHPBA, Inspección General de Milicias, leg. 48, exp. 417.

AHPBA, Inspección General de Milicias, leg. 48, exp. 375.

AHPBA, Ministerio de Gobierno, año 1874, leg. 21, exp. 843, fs. 190-191.

AHPBA, Inspección General de Milicias, leg. 48, exp. 419.

AHPBA, Inspección General de Milicias, leg. 48, exp. 427.
} 
Como consecuencia de los primeros esfuerzos que realizaron las autoridades locales para reclutar guardias nacionales que estuviesen dispuestos a defender al Gobierno, el 3 de octubre, el comandante de la Guardia Nacional de Morón, Miguel Naón, informaba al ministro de Gobierno que en ese pueblo habían reunido 2069 guardias nacionales de diferentes partidos del norte y centro-norte de la provincia de Buenos Aires. Mientras que algunos jefes milicianos lograron movilizar centenares de hombres, otros solo sobrepasaron las pocas decenas. El comandante Lamela había movilizado 346 hombres de Carmen de Areco; el comandante Saraví 146 de San Andrés de Giles; el comandante Castex 136 de Morón y 37 de Matanza; el comandante Dillon 55 de Merlo, 58 de Moreno y 43 de Las Heras; el mayor Perin 216 de Chivilcoy; el capitán Visillac 52 de San José de Flores, 45 de San Martín y 30 de San Isidro; el comandante López 124 de San Antonio de Areco; el comandante Benítez 88 de Pilar; el capitán Carrera 100 de Luján, y el comandante Bosch 198 de Lobos, 56 de Monte y 344 de Saladillo ${ }^{50}$.

Más hacia el sur de la provincia, donde los mitristas dominaban la situación, la resistencia que pudieran esgrimir las autoridades locales era muy valorada por el Gobierno provincial. Hortensio Miguens, comandante de la Guardia Nacional de Ayacucho y Arenales y reconocido partidario autonomista, desarrolló una labor destacada en la lucha contra los mitristas hasta que fue interceptado y capturado por las fuerzas de Nicolás Ocampo y Julián Murga. El 29 de septiembre informaba al ministro de Gobierno que había reunido doscientos guardias nacionales, para los cuales pedía sables y carabinas ${ }^{51}$.

Por lo tanto, una de las primeras medidas que tomaron los jefes rebeldes fue remplazarlas por personas que les respondieran y fueran adictas al mitrismo ${ }^{52}$. En el caso de Tandil, el partidario alsinista, Juan Fugl, expresaba en sus memorias que el coronel Benito Machado había reunido a un grupo grande de seguidores y que con figuras de renombre local llegaron al pueblo y destituyeron al juez de paz a los integrantes de la corporación municipal y al comandante de la Guardia Nacional del partido y fueron remplazados por personas leales a Machado, las cuales quedaron como «autoridades supremas ${ }^{53}$. A partir de entonces, el nuevo juez de paz de Tandil, que hasta ese momento se había desempeñado como director del Banco Provincia de la localidad, Guillermo Randel, pasó a ser una pieza clave de los revolucionarios

\footnotetext{
50 AHPBA, Ministerio de Gobierno, año 1874, leg. 21, exp. 843, fs. 172-173. Además, se esperaba reunir 250 hombres más de la Guardia Nacional de 25 de mayo.

51 AHPBA, Inspección General de Milicias, leg. 48, exp. 439.

52 Del Mármol (1876).

53 Larsen de Raval (1989): 440-441.
} 
en ese partido, ya que debía cumplir las directrices que recibía de Machado. El 7 de octubre de 1874, este último le ordenaba a aquel que entregara todos los fusiles que tuviera ese juzgado y que colaborara en todo lo necesario, a fin de poder armar las compañías de infantería de ese pueblo ${ }^{54}$. Con el propósito de cumplir tal mandato, una de las primeras medidas que adoptó Randel fue reemplazar a los alcaldes de los cuarteles que estaban cercanos al alsinismo por vecinos partidarios del mitrismo o aquellos que habían mostrado «simpatías" por la revolución, quienes fueron encomendados para hacer lo mismo con los tenientes alcaldes bajo sus órdenes 55 .

Para el partido de Las Flores disponemos de un relato similar sobre las acciones que llevaron a cabo los jefes revolucionarios Ignacio Rivas y Nicolás Ocampo, al momento de reemplazar a las autoridades locales. En este caso, la narración de los hechos pertenece al juez de paz que había sido sustituido y fue enviada al ministro de Gobierno el 24 de octubre, cuando se pudieron restablecer las comunicaciones oficiales con Buenos Aires. El 2 de octubre habían ingresado al pueblo de Las Flores las fuerzas revolucionarias de Ocampo, con el propósito de lograr la rendición de la Guardia Nacional de ese partido, que había sido reunida por el comandante Villanueva. En ese caso no se produjo ningún enfrentamiento, debido a que los milicianos de ese pueblo se desbandaron en diversas direcciones y no secundaron las órdenes de Villanueva, ante la superioridad del Ejército Constitucional. Habiendo transcurrido una hora de este episodio, este último entró al pueblo y destituyó al juez de paz y, en su lugar, designó a Alejo Aveleyra, quien estaba encargado del correo y de la venta de papel sellado. Aveleyra apresó al antiguo juez de paz, al secretario de la Municipalidad y a otros vecinos y remplazó a todos los integrantes de la Corporación Municipal por personas de su cercanía ${ }^{56}$.

Míguez plantea que el grueso de las fuerzas revolucionarias estuvo conformado por guardias nacionales de los partidos fronterizos, donde el movimiento contaba con el apoyo de los jueces de paz o los comandantes de la Guardia Nacional ${ }^{57}$. Cordero y Barbuto destacaron que, conjuntamente con estos, la presencia de personajes con prestigio y poder, como algún hacendado local, fueron fundamentales en la movilización militar, lo que evidencia la presencia de agentes reclutadores de los rebeldes que en ese momento no ejercían ningún cargo oficial ${ }^{58}$. Por lo tanto, queremos destacar que la

\footnotetext{
54 Archivo Histórico de Tandil [AHT], caja 29, leg. de 1874, doc. 303.

55 AHT, Libro copiador de notas a los Alcaldes del Partido, años 1872 a 1879, pp. 92-93.

56 AHPBA, Ministerio de Gobierno, año 1874, leg. 20, exp. 842, fs. 330-333.

57 Míguez (2011): 34-35.

58 Cordero y Barbuto (2012): 163-164.
} 
Guardia Nacional no siempre fue movilizada por sus comandantes, sino que, en determinadas ocasiones, jefes militares y milicianos que habían construido gran parte de su poder en la campaña desde aquella institución, pero que por entonces se hallaban alejados de sus puestos de mando, tuvieron un rol esencial en la conformación del Ejército Constitucional. Benito Machado, Matías Ramos Mejía y Jacinto González son claros ejemplos de ello, ya que por entonces eran destacados vecinos y propietarios rurales de la campaña sur, sudeste y oeste, respectivamente, que habían tenido una importante trayectoria militar en la frontera ligada al mitrismo, a la Guardia Nacional y al Ejército de Línea, pero que por entonces hacía varios años que estaban alejados de toda actividad militar oficial. A continuación, examinamos el rol que tuvo el primero en la formación de las fuerzas rebeldes en el sur de Buenos Aires.

\section{BENITO MACHADO Y EL REGIMIENTO SOL DE MAYO: VÍNCULOS Y LEALTADES EN LA REVOLUCIÓN}

En los años finales de la década de 1870, el ingeniero francés Alfred Ebelot, que estuvo al servicio del Ejército argentino durante la expansión de la frontera sur del país entre 1875 y 1879, redactó una serie de crónicas en las cuales narró su experiencia en Argentina. En una de ellas, afirmó:

La Guardia Nacional fue el instrumento de perpetuos desórdenes; en vano la Constitución había rodeado de recaudos la convocatoria de las milicias rurales: bastaba con que una ilegalidad audaz, pero frecuente, diera a un ambicioso de provincia el pequeño recurso que ponía en marcha la maquinaria, para obtener como resultado batallones a través de los campos, lanza en ristre, enarbolando programas políticos ${ }^{59}$.

Con esta frase podríamos identificar, por ejemplo, al accionar que desarrollaron González, Ramos Mejía y Machado en la revolución de 1874. Ahora bien, ¿en qué consistía dicha «maquinaria»? y ¿qué estrategias utilizaron para movilizar "batallones a través de los campos»? Estas preguntas constituyen excelentes puntos de partida para indagar los mecanismos que implementaron con el fin de organizar el levantamiento y reclutar hombres para la causa mitrista en la frontera sur de Buenos Aires. Aquí nos concentraremos en uno de ellos: el coronel Benito Machado. Un breve repaso sobre su trayectoria nos

59 Ebelot (1968): 131-133. 
permitirá contextualizar y comprender su participación en dicho episodio en favor del mitrismo ${ }^{60}$.

Machado nació en Buenos Aires, el 3 de abril de 1823, en el seno de una familia de propietarios rurales. Luego de que su padre Jacinto y su hermano Mariano fueran ejecutados por su participación en el movimiento antirrosista que protagonizaron los estancieros del sur de la provincia de Buenos Aires a finales de 1839, migró con su familia a Montevideo al año siguiente. En marzo de 1852, regresó a Buenos Aires para ocuparse de la administración y producción de sus tierras. A partir de ese año y hasta el 8 de noviembre de 1868, ocupó funciones de gobierno en Buenos Aires y de mando en el Ejército Nacional. En el sur bonaerense, participó a favor de la revolución del 11 de septiembre de 1852 y combatió al sitio que las fuerzas federales de Hilario Lagos le hicieron a la capital porteña. En 1853, fue alcalde de cuartel y, de facto, comandante militar de Lobería, función en la que fue nombrado al año siguiente. Al mismo tiempo, en 1854 y 1855 ocupó el cargo de juez de paz de ese distrito. El 1854 fue ascendido a comandante de Guardias Nacionales y se le encargó la organización del Regimiento 14. En 1857, fue comisionado para organizar el Regimiento 17, que meses después se denominaría «Sol de Mayo». Por sus acciones en los combates contra los indígenas, en 1858 ascendió a coronel graduado de caballería de Línea y, en 1859, ocupó el cargo de segundo jefe de la Frontera Sud.

El perfil militar de Machado también se forjó en las intervenciones que tuvo en varios de los conflictos que formaron parte de la disputa por la construcción del Estado nacional. Reclutó cerca de un millar de hombres del Regimiento Sol de Mayo para defender la frontera bonaerense ante el avance de las fuerzas de la Confederación Argentina luego del combate de Cepeda (1859). Poco más de un año después, en 1861, su actuación en "Pavón» y "Cañada de Gómez» fue más resonante. En esa ocasión, aportó una división de más de 1000 plazas de caballería, de la cual formó parte el mencionado regimiento. El 5 de enero de 1860, durante la gobernación de Bartolomé Mitre, fue designado jefe de la Frontera Costa Sud y ocupó ese cargo, incluso, cuando este presidió el país, entre 1862 y 1868. En 1865, al iniciarse la guerra de la Triple Alianza contra Paraguay, fue nombrado, de forma interina, comandante general de las fronteras Sud y Costa Sud. Entre 1868 y 1879, no ocupó ningún cargo de gobierno, como así tampoco puestos de mando en el Ejército Nacional, aunque mantuvo su rango de coronel de Línea. Su alejamiento del comando en la frontera significó un duro golpe para la construcción de poder

60 Para ello, recurrimos a Archivo General del Ejército, legajo núm. 7312; del Valle (1908); Romeo (1934); Yangilevich (2006) y Canciani (2012). 
fuera de la región sur de la provincia de Buenos Aires; aunque, su destacada participación en el hecho de armas que estudiamos lo reposicionarían frente al gobierno bonaerense, pocos años más tarde.

La carrera política y militar de Benito Machado estuvo estrechamente ligada a la de Bartolomé Mitre, de allí que la revolución de 1874 lo tuviera como uno de sus protagonistas. Cuando este último intentó oponerse al resultado de las elecciones que le fueron desfavorables, el coronel lo acompaño como en todas las ocasiones anteriores ${ }^{61}$. Fue uno de los principales líderes de la revolución en el sur de la campaña y la frontera bonaerense, sobre todo por su capacidad de reclutamiento y movilización militar. Si bien mantenía su rango de coronel de caballería de Línea, su intervención en la revolución estuvo enmarcada en lo que Irurozqui ha denominado "ciudadanía armada popular», es decir, la acción militar de los civiles dentro de instituciones firmemente jerarquizadas - como la Guardia Nacional-, que dirigían sus movimientos y contenían el desorden y los desbordes violentos. Los sublevados apelaban al derecho de resistencia del pueblo frente al despotismo de los dirigentes para restaurar por la fuerza un orden legal pervertido por el abuso de autoridad ${ }^{62}$.

Los antiguos biógrafos de Machado destacaron la importancia que tuvo al momento de conformar las fuerzas revolucionarias de 1874, aunque sus palabras estuvieron teñidas por la simpatía que este les despertaba y cargadas de una fuerte subjetividad. Romeo sostuvo: «Más de mil gauchos rodearon al viejo soldado y a la gloriosa bandera del Regimiento "Sol de Mayo" ${ }^{63}$. Del Valle destacó que formó una división de mil voluntarios de caballería pertenecientes a dicho regimiento, con la que se plegó al ejército de Mitre. Afirmó:

Bastaba una citación trasmitida verbalmente ya fuera por intermedio de los alcaldes, ó de los soldados, ó de cualquier vecino que involucrara el nombre del Coronel; designando paraje, día y hora para reunirse; para que sin pérdida de tiempo concurrieran los G. N. con caballo de tiro, buscando la incorporación de su jefe. Tenían pasión, cariño, respeto, por este hombre [...], por eso, apenas tenían conocimiento de una orden ó citación, todos corrían presurosos á formar á su llamado ${ }^{64}$.

No obstante, diversas investigaciones han mostrado que la movilización de hombres para la guerra por parte de los comandantes y diferentes

\footnotetext{
${ }_{61}$ Yangilevich (2006): 224.

62 Irurozqui (2015): 207.

63 Romeo (1934): 83.

64 Del Valle (1908): 85-86.
} 
caudillos territoriales no fue tan sencilla ni de forma automática como reseña del Valle. Una citación militar correspondida estaba precedida por una serie de estrategias mediadas por diversas formas de relación entre el líder y los milicianos. Además de la implementación de mecanismos coercitivos — sobre los cuales ya volveremos-, recurrieron a otros más negociados, como el otorgamiento del fuero militar; la exención en el pago de los arriendos por el usufructo de la tierra; la entrega de estas en propiedad por servicios de armas; la compensación de motivaciones materiales inmediatas, como la moneda, el consumo de carne en los campamentos, la provisión de ropa y calzado durante la campaña, la permisividad ante el saqueo a los oponentes y sus propiedades; la asistencia económica y la protección cotidiana frente a la autoridad, lo que generaba lazos de solidaridad; y, finalmente, la motivación política de los paisanos, por su identificación con el líder y la causa que este defendía, entre otros ${ }^{65}$.

En lo que respecta a esta última cuestión, Machado utilizó la proclama como primer elemento motivador para reunir a los guardias nacionales. Con ella buscaba incentivar el "patriotismo» de los habitantes del sur de la campaña bonaerense y sumarlos de forma voluntaria al movimiento revolucionario que protagonizaba. Al momento de iniciar el reclutamiento, el 28 de septiembre de 1874 lanzó el siguiente manifiesto:

La causa de la libertad seriamente amenazada por un círculo de demagogos que apoderándose del poder por medio del fraude, de la violencia y de la opresión, necesita hoy [...] del patriótico concurso de los buenos ciudadanos para dar en tierra una vez por todas con esos caudillos irresponsables, que han permitido humillar impunemente el honor del pueblo argentino.

La Constitución Nacional iniciada y llevada a su término por el patriota Brigadier General D. Bartolomé Mitre con aplauso no solamente de los pueblos argentinos, sino también de la Europa toda, ha sido para los hombres que hoy combatimos, el juguete de sus ambiciones, y la burla también á los derechos y prerrogativas de todos los habitantes de la República. [...].

Es pues en defensa de la causa de la libertad que antes de ahora habéis defendido. Es en defensa de la Constitución Nacional, que todos los pueblos de la República han protestado con las armas en la mano, para no permitir un momento más el escándalo, que han dado a la República y al mundo entero, unos cuantos hombres estraviados, cuyo campamento hoy es solo la Ciudad de Buenos Aires.

65 Mata de López (2000, 2008); Schmit (2004, 2015); Fradkin (2006); de la Fuente (2007) y Lanteri (2011). 
Compatriotas, á las armas nos han dicho ya los beneméritos Generales Taboada, Rivas, Arredondo, Gelly, Vedia; los Coroneles Borges, Ocampo, Murga, Ramos Mejía; los Jefes de la Escuadra, y tantos otros jefes oficiales y respetables ciudadanos, que han presentado al Brigadier General D. Bartolomé Mitre, todas las fuerzas de su dependencia y sus poderosos elementos para sostener la libertad y la Constitución, y hacerla triunfar nuevamente en todos los ámbitos de la República.

Guardias Nacionales del regimiento «Sol de Mayo». Yo también os digo á las armas, que vuestro jefe compañero y amigo, en todo tiempo ha sido el soldado de la Ley y del orden, por cuya causa habéis peleado bajo mis órdenes, y la victoria siempre premió vuestro patriotismo.

CIUDADANOS ARMADOS - El respeto a la vida y a la propiedad de nacionales y estrangeros siempre fue nuestra bandera, y no hay más enemigos que los que la combaten.

La bandera de la libertad, de la Constitución y de los derechos de los pueblos, es la que hoy flamea en todos nuestros campamentos y levantándola hacia el cielo y poniendo por testigo al Dios de los ejércitos de la santidad de nuestra causa, acompañadme á decir:

Viva la Constitución Nacional.

Viva la República Argentina.

Viva el Brigadier General D. Bartolomé Mitre ${ }^{66}$.

Como vemos, Benito Machado creía que ese "círculo de demagogos», que había obtenido el triunfo en las elecciones presidenciales de 1874 "por medio del fraude, de la violencia y de la opresión», se había burlado de la Constitución Nacional, al considerarla un «juguete de sus ambiciones» y del pueblo argentino, al elevarse por encima de sus derechos y prerrogativas. Por ello, la revolución necesitaba del apoyo de los «buenos ciudadanos» — esos guardias nacionales del Regimiento Sol de Mayo, que hasta seis años atrás habían peleado bajo sus órdenes - para dar por tierra con esa humillación y defender la Constitución. Según Machado, esa Guardia Nacional debía ser movilizada para preservar «los derechos y prerrogativas de todos los habitantes de la República» y la Constitución Nacional. La tiranía podía ser personificada por cualquier individuo; incluso, por el presidente de la Nación o el gobernador de alguna provincia. A causa de ello, en la revolución de 1874 la Guardia Nacional se movilizaba para enfrentar a las propias instituciones del Estado, pues desde ellas se negaba y se desconocía la Constitución Nacional, aquella que, en palabras del coronel, había sido «iniciada y llevada a su

66 Del Mármol (1876): 547-548. Las mayúsculas corresponden al original. 
término por el patriota Brigadier General D. Bartolomé Mitre con aplauso no solamente del pueblo argentino sino también de la Europa toda».

En la proclama, observamos que si la milicia podía movilizarse con el propósito de defender la libertad de los ciudadanos y las instituciones del Estado, también debía hacerlo cuando el mitrismo se viera desfavorecido en algún proceso electoral o cuando lo necesitara para retornar al poder por medio de mecanismos no institucionales — aunque legítimos en la cultura política decimonónica-, como lo era una revolución que impugnara el resultado de un sufragio presidencial. Si bien la convocatoria iba dirigida al conjunto de la población — «compatriotas del sur» y «ciudadanos armados»— también llamaba a los "Guardias Nacionales del Regimiento "Sol de Mayo"», que habían sido sus compañeros de combate contra los indígenas y en las guerras posrosistas. Apelaba a las nociones de camaradería que había sabido construir años atrás, desde la comandancia de ese cuerpo ${ }^{67}$, con el objetivo de que se le unieran en esta "cruzada patriótica». Les recordaba que había sido su jefe y, como tal, los distinguía del resto de la población, reconociéndolos como miembros del extinto regimiento, identificado, indudablemente, con el mitrismo.

La numeración de los regimientos de la Guardia Nacional había sido abolida en 1870, pero la identificación de Machado y los guardias nacionales de Tandil, Lobería, Necochea y Tres Arroyos (sur de la provincia de Buenos Aires) con aquel regimiento era tal, que el coronel lo evocaba para reflotar los sentimientos de pertenencia y de camaradería que pudieran movilizar a sus antiguos integrantes a tomar las armas para defender la causa mitrista. Como vemos, la identificación de Machado y «sus» guardias nacionales con el obsoleto Regimiento Sol de Mayo, que pregonaban Antonio del Valle y Salvador Romeo en sus biografías, no era en vano.

Este regimiento fue un espacio desde el cual Machado constituyó vínculos con sus milicianos. La identificación de estos con el cuerpo al que pertenecían se tornaba un importante vehículo para construir confianza, cohesión grupal y sentimientos de camaradería entre sus integrantes. Pero, no fue solo la identificación de integrar un regimiento lo que generaba pertenencia entre los milicianos, sino, más aún, formar parte de un grupo que debió responder a las órdenes de un determinado jefe ${ }^{68}$. Estos vínculos se activaron en situaciones cotidianas y en momentos de fuerte conflictividad política y militar, como ocurrió con la revolución de 1874 .

Ahora bien, ¿qué otros mecanismos pusieron en práctica Machado y sus oficiales para incentivar la movilización miliciana en el sur de la provincia de

67 Canciani (2012): 149-156.

68 Idem: 152-155. 
Buenos Aires y conformar la División Sol de Mayo del Ejército Constitucional, compuesta por más de un millar de guardias nacionales? De la lectura de las crónicas que dejaron algunos habitantes de Tandil que vivieron la revolución se desprende la importancia que tuvieron los vínculos de Machado con políticos, jefes milicianos y hacendados locales al momento de reclutar sus fuerzas, ya que el apoyo que recibió de parte de las familias Figueroa, Gómez y demás mitristas de la zona fue clave ${ }^{69}$. Emilio Delpech, inmigrante francés llegado a Tandil en 1869, dejaba constancia en sus relatos de que

la revolución de 1874 contó con la cooperación decidida de los Gómez, que no solamente hicieron entrega al general [Mitre] de una suma crecida para contribuir a la costosa organización de un movimiento partidario de tal magnitud, sino que todo el personal de su importante estancia «San Ciriaco», con el encargado del establecimiento, un distinguido militar, al frente, se puso bajo las órdenes del coronel Machado y José Ciriaco Gómez, para juntarse a las fuerzas, ya numerosas, que formaban el improvisado ejército revolucionario con el General Mitre a la cabeza ${ }^{70}$.

Otro de los mecanismos que implementó fue comisionar a su hijo Julián, a fin de reclutar hombres y recursos necesarios para la revolución. Ante la imposibilidad de presentarse él mismo en el lugar de los hechos, la familia nuclear de Machado se constituyó en un punto de referencia clave desde el cual el coronel podía hacer valer su influencia y posición de poder en el sur bonaerense. En Tandil, el joven se unió a la partida que comandaba a Lobería Pedro Sáenz Valiente, terrateniente de ese partido que había sido juez de paz y comandante de la Guardia Nacional, en busca de hombres, caballos y

69 Benito Machado estableció sólidas relaciones de parentesco con el matrimonio de José Ramón Gómez y Pilar López de Osornio y con las familias Figueroa y Montenegro. Sus hijas Ángela y Rosaura se casaron con José Ciriaco Gómez, hijo del matrimonio Gómez-López de Osornio. Este último fue un prestigioso hacendado del sur bonaerense y comandante de la Guardia Nacional de Tandil durante la década de 1870. Por su parte, Juan Adolfo Figueroa, juez de paz durante los primeros años de la década de 1870, estaba casado con Pilar Gómez, hermana de su yerno: uno de sus hijos contrajo matrimonio con Sara, una de las nietas de Machado. Por otro lado, el coronel Antonino López Osornio, quien lo sucedió en el mando de la Frontera Costa Sud, en 1866, estaba emparentado con Pilar, su consuegra. A su vez, Alejo Machado — primo hermano del coronel- se casó en segundas nupcias con Marcelina Gómez, hermana de Ramón, quien era su consuegro. Reguera (2003): 24.

Delpech (1944): 159-160. 
dinero. Al llegar a Lobería, Sáenz Valiente decidió no reemplazar a las autoridades locales, ya que tanto el juez de paz como el comandante eran partidarios mitristas. El lugar de reunión de la Guardia Nacional fue la estancia Sarandí. Allí debían presentarse los milicianos del cuartel en la que esta estaba emplazada y donde los comisionados Julián Machado y Juan Calamaro debían reunir sus contingentes y caballos. El joven Machado logró sumar 22 hombres y 75 caballos. En total, el partido en cuestión aportó 147 guardias nacionales, con los cuales se conformó el Escuadrón Lobería, que integraría la División Sol de Mayo del Ejército Constitucional ${ }^{71}$.

Como afirma Míguez, las fuentes no nos narran cuánto de voluntario y de compulsivo tuvo la reunión de la Guardia Nacional en Lobería, pero lo más probable es que haya sido un poco de ambas cosas. Puede que algunos se hayan identificado con el mitrismo y, sobre todo, con sus partidarios locales; que otros estuvieran ligados por obligaciones y lazos clientelares para con Sáenz Valiente; algunos buscaran una forma de obtener réditos económicos ante la promesa de paga y los redituables saqueos que permitía la "guerra de recursos» y, finalmente, es probable que más de uno se viera forzado a sumarse a la partida, ante la amenaza de un piquete armado frente a su rancho, sin importar demasiado cuál era su definición política ${ }^{72}$.

Algunos contemporáneos han dejado testimonio de la inclemencia militar de Machado y el temor que solía despertar en los soldados y milicianos que luchaban bajo sus órdenes. En sus memorias, Juan Fugl narró que en «no pocas veces había hecho eliminar de un tiro a personas, sin interrogatorio ni juzgamiento, solo porque le desagradaban $»^{73}$. Por su parte, Teófilo Gomila, ayudante de Ignacio Rivas en la revolución, relató cómo Machado ordenó ejecutar a dos ladrones que capturaron sus partidas en las cercanías del pueblo de Azul:

La división hizo alto, sus mil doscientos hombres formaron en línea de batalla. Doce lanceros echaron pié a tierra, los criminales entraron al Circo y en diez minutos fueron acribillados á lanzasos. La división siguió marcha — desfilando por delante de los cadáveres- [...]. Los habitantes de Azul encontraron [...] dos cuerpos acribillados á lanzasos en cuyos pechos [...] se leía esta inscripción: «Ladrones y asesinos tomados infraganti y ejecutados por orden del Coronel Machado ${ }^{74}$.

\footnotetext{
Del Mármol (1876): 126-132.

Míguez (2011): 45.

Larsen de Raval (1989): 444.

74 Teófilo Gomila, «La revolución de 1874». De Jong y Satas (2011): 239. Para del Mármol (1876: 363-364), se habría tratado de dos desertores de su división.
} 
Si bien este tipo de castigos no eran tan frecuentes — de hecho, Machado, una vez terminada la revolución, debió enfrentar un proceso judicial, además del Consejo de Guerra que se le formó junto a los otros jefes rebeldes-, no era la primera vez que tomaba ese tipo de represalias frente a inconvenientes que podrían poner en peligro la disciplina de sus fuerzas en tránsito o en la previa a un enfrentamiento armado. En diciembre de 1859, durante el sitio de Pedro Rosas y Belgrano al pueblo de Azul, luego de la derrota bonaerense en la batalla de Cepeda, un teniente del Regimiento Sol de Mayo desertó junto a un grupo de milicianos, con el propósito de evitar el combate y asolar la campaña. Una vez capturado, fue sometido a una Junta de Guerra y ejecutado ${ }^{75}$. A más de los vínculos que había establecido con sus guardias nacionales, la figura de hombre rudo y de jefe militar inclemente, que supo construir en la frontera, constituyó una estrategia complementaria a aquellas prácticas más negociadas que utilizó para garantizar la movilización miliciana y mantener la disciplina de los batallones en marcha cuando esta pareciera debilitarse ${ }^{76}$.

Pese a la movilización masiva que se vivió en el sur de la campaña bonaerense el ejército mitrista fue derrotado. Luego de una serie de pequeños enfrentamientos entre las fuerzas de vanguardia de ambos bandos, el 26 de noviembre de 1874 chocaron en la batalla de La Verde el Ejército Constitucional, que por entonces rondaba los cinco mil hombres, y las fuerzas nacionales que comandaba José Inocencio Arias, que apenas superaban los ochocientos efectivos, entre soldados de Línea y guardias nacionales. La inferioridad numérica de las fuerzas gubernamentales no fue determinante para el resultado del enfrentamiento. Por su posición estratégica y por las mejores armas que disponían, acribillaron a balazos de Rémington la carga de la caballería del ejército mitrista — dentro de la cual se encontraba la División Sol de Mayo al mando de Benito Machado-, propiciándoles la derrota y determinando el fin de la revolución en la provincia de Buenos Aires. Días más tarde, el 7 de diciembre, las fuerzas de Arredondo serían derrotadas por las que comandaba Julio Roca en la batalla de Santa Rosa. Mitre y los principales jefes revolucionarios fueron apresados y gran parte de los 2136 guardias nacionales que todavía se encontraban en el campamento mitrista licenciados, siendo

Míguez (2003): 26.

76 En una carta que Benito Machado le escribió a Germán de Elizalde (hermano de Rufino, ministro de Relaciones Exteriores y Culto del Gobierno de Mitre) le explicaba: «Como yo tengo amigo la bentaja de conocer a todos mis paisanos de estos Departamentos [de la frontera] es que [...] no estrañe que haveses es preciso hacer sentir la autoridad, y en estas alturas mas que en otros puntos». AGN, Sala VII, Fondo Rufino de Elizalde, leg. 14, fs. 731-732. 
destinados algunos de ellos al servicio de frontera. Si bien hubo algunos movimientos en el sur bonaerense que intentaron resistir por algunos días ${ }^{7}$, lo cierto es que el Gobierno provincial retomó rápidamente el control de los partidos que habían sido dominados por los rebeldes.

\section{CONSIDERACIONES FINALES}

La Guardia Nacional y sus comandantes tuvieron una destacada participación en la revolución de 1874, tanto en defensa del Gobierno como del lado de los revolucionarios. El primero reunió sus fuerzas siguiendo los canales institucionales que disponían su movilización, mientras que los segundos lo hicieron a través de prácticas ilegales — aunque legítimas-, debido a que no contaban con las autorizaciones del presidente y del gobernador para ello. Sin embargo, los jefes mitristas utilizaron otras estrategias que hicieron posible la reunión de un ejército nutrido. Algunos de ellos, como Rivas, Borges, Ocampo, Murga, Segovia y Leyría, disponían de fuerzas del Ejército de Línea a su cargo; $y$ otros con gran experiencia militar, pero sin ellas, como Machado, Ramos Mejía y González, gozaban de fuerte arraigo local en diferentes zonas de la campaña bonaerense. Más allá de no contar con el respaldo estatal, utilizaron mecanismos compulsivos y coactivos para garantizar el reclutamiento, como la amenaza o el uso de la fuerza y la leva indiscriminada, y otros más consensuados, en donde apelaban a los vínculos personales y colectivos de camaradería que habían construido desde su rol de jefes de regimientos de Guardias Nacionales y por la influencia que tenían en los partidos de la campaña que habitaban.

En este tipo de episodios, donde era necesario reclutar cientos y/o miles de hombres para potenciales enfrentamientos armados, ejercer la función de comandante de la Guardia Nacional no garantizaba dicha movilización, ya que no siempre tener un cargo de gobierno se correspondía con el verdadero ejercicio del poder. Si bien en el norte de la provincia de Buenos Aires y la campaña más cercana a la capital los comandantes desarrollaron una destacada labor para reducir posibles focos insurreccionales y reunir hombres bajo la bandera del Gobierno, en ciertos territorios — como el sur de la provincia de Buenos Aires y la frontera- los caudillos mitristas mantuvieron su preeminencia y el control de la Guardia Nacional de los partidos de esa zona, pese a no ser designados jefes por el dominio del alsinismo en la primera

AHT, caja 29, leg. de 1874, doc. 351 y AHT, Juzgado de Paz, Cartas al juez de Paz, años $1874 / 1880$, signatura 1178 . 
magistratura provincial. En este caso, el poder de mando en la Guardia Nacional no se lograba por la concesión de la autoridad legítima que hacía el gobernador sino por lograr hacerse obedecer entre los sujetos de reclutamiento y saber sostener el lugar de privilegio que tenían en los distritos de la campaña y la frontera.

La revolución de 1874 reflejó que el Estado nacional y su Ejército se consolidaban a pasos agigantados y que los focos rebeldes que se generaron al interior de este último ya no podían doblegar al resto de la fuerza de Línea que estaba subordinada al presidente de la Nación, como jefe de Estado, y no a las ambiciones políticas de jefes partidistas. Durante su gobierno, Sarmiento había logrado desmontar la lógica regional-militar en el Ejército y, en su lugar, incorporar una dinámica centralista materializada en un sistema de coroneles leales elegidos desde el poder central, que operaban a partir de sus directivas ${ }^{78}$. Sin embargo, en la provincia de Buenos Aires, la Guardia Nacional siguió influenciada por los poderes locales. En este sentido, la revolución demostró la capacidad de movilización armada de los caudillos territoriales que resistían a la pérdida de su poder en los espacios locales a los cuales se habían confinado, luego de su alejamiento de los principales puestos de mando del Ejército de Línea en los años finales de la década de 1860. En este sentido, si la Guardia Nacional fue un espacio desde el cual diferentes individuos pudieron construir sólidas carreras militares, que los transformaron en importantes líderes políticos en las regiones donde actuaban, también representó un ámbito desde el cual resistieron la pérdida de los espacios de poder que habían ganado a través de ella.

En el caso de Benito Machado, su participación en la frustrada revolución de 1874 llevó a que, años después, el Gobierno de Buenos Aires reconociese su capacidad de convocatoria y de movilización militar, al ser nombrado jefe de la Décima Circunscripción de la Guardia Nacional de Campaña, integrada por los partidos de Rauch, Ayacucho, Tandil, Mar Chiquita, Lobería y Balcarce. Desde ese puesto, organizó la movilización armada para la revolución de 1880 en el sur-sureste provincial, que enfrentó al Gobierno bonaerense con las autoridades nacionales ${ }^{79}$. Por lo general, se ha sostenido que fue perdiendo su posición privilegiada de poder en la frontera sur de Buenos Aires desde mediados de la década de 1860 y que, finalmente, fue desplazado de ella una década más tarde, como consecuencia de su participación en la revolución mitrista. Sin embargo, argumentamos que el coronel Machado pudo mantener su poder político, militar y simbólico en el sur de la campaña

78 Macía (2014): 227.
79 Canciani (2014). 
bonaerense, después de la derrota del mitrismo a nivel nacional, en 1874. Si aquel acontecimiento demostró la progresiva consolidación del Ejército de Línea y el creciente poder militar del Estado nacional, también sirvió para que los caudillos territoriales mitristas del sur bonaerense pudieran demostrar su importancia en la política provincial y su capacidad de movilización electoral y militar. En este sentido, la revolución de 1880 constituyó una excelente ocasión para confirmar que Benito Machado y aquellos actores mantenían su liderazgo en esa región. Pero ello, ya corresponde a otra historia.

\section{Bibliografía}

Barbuto, L. y de Jong, I. (2012). De la defensa de las fronteras al conflicto faccional: preparando la revolución mitrista en el sur de Buenos Aires. Revista Sociedades de Paisajes Áridos y Semiáridos, 4 (6), 35-65. Disponible en: http://paisajesaridos.org/doc/ rp6.2.pdf.

Bragoni, B. (2002). La agonía de la Argentina criolla. Ensayo de historia politica y social, c. 1870. Mendoza: Editorial de la Universidad Nacional de Cuyo.

Canciani, L. (2012). De las comandancias de frontera a las Guardias Nacionales. El liderazgo del coronel don José Benito Machado en el sur de la campaña bonaerense [tesis de licenciatura inédita]. Universidad Nacional del Centro de la Provincia de Buenos Aires.

- (2014). «Tan pródiga para los mitristas y las rebeliones». La revolución de 1880 en el sur de la campaña bonaerense: Guardia Nacional y liderazgos locales. Coordenadas, 1 (1), 143-177. Disponible en: http://ppct.caicyt.gov.ar/index.php/coordenadas/article/ view/4738/4405.

- (2015). La competencia política en la campaña de Buenos Aires. Comandantes de la Guardia Nacional y caudillos locales en las elecciones legislativas nacionales del $1 \mathrm{de}$ febrero de 1874. Revista Latino-Americana de História, 4 (13), 46-66. Disponible en: http://projeto.unisinos.br/rla/index.php/rla/article/view/604/558.

Carmagnani, M. (2007). Campos, prácticas y adquisiciones de la historia política latinoamericana. En G. Palacios (coord.). Ensayos sobre la nueva historia politica de América Latina, siglo XIX (pp. 31-43). México: El Colegio de México.

Cordero, G. y Barbuto, L. (2012). La movilización de los sectores subalternos en la revolución mitrista de 1874. Anuario del Centro de Estudios Históricos, 12, 153-171. Disponible en: http://dialnet.unirioja.es/servlet/articulo?codigo $=4968672$

Daghero, S. (2014). Las facciones y las armas: la Revolución de 1874 en Córdoba y Cuyo. Coordenadas, 1 (1), 118-142. Disponible en: http://ppct.caicyt.gov.ar/index.php/coordenadas/article/view/47 37/4404.

De Jong, I. (2012). Facciones políticas y étnicas en la frontera: los indios amigos del Azul en la Revolución Mitrista de 1874. Nuevo Mundo Mundos Nuevos. Disponible en: 10.4000 /nuevomundo.62496.

— y Satas, V. (2011). Teófilo Gomila. Memorias de frontera y otros escritos. Buenos Aires: El Elefante Blanco. 
De la Fuente, A. (2007). Los hijos de Facundo. Caudillos y montoneras en la provincia de La Rioja durante el proceso de formación del Estado nacional argentino (1853-1870). Buenos Aires: Prometeo Libros.

Del Mármol, F. (1876). Noticias y documentos sobre la revolución de septiembre de 1874. Buenos Aires: Imprenta de M. Biedma.

Delpech, E. (1944). Una vida en la gran Argentina. Buenos Aires: Peuser S.A. Impresores.

Del Valle, A. (1908). El coronel Don Benito Machado. Apuntes históricos. Tandil: Edición del autor.

Ebelot, A. (1968). Frontera Sur. Recuerdos y relatos de la Campaña del Desierto (1875-1879). Buenos Aires: Editorial Kraft.

Fradkin, R. (2006). La historia de una montonera. Bandolerismo y caudillismo en Buenos Aires, 1826. Buenos Aires: Siglo Xxi Editores.

Garavaglia, J. C. (2012). Prólogo. En J. C. Garavaglia, J. Pro Ruiz y E. Zimmermann (eds.). Las fuerzas de guerra en la construcción del Estado. América Latina, siglo XIX (pp. 9-13). Rosario: Prohistoria Ediciones/SBLA-Universitat Pompeu Fabra.

Goldman, N. y Salvatore, R. (2005). Caudillismos rioplatenses. Nuevas miradas a un viejo problema. Buenos Aires: Eudeba.

Gorostegui de Torres, H. (1972). Historia argentina. La organización nacional. Buenos Aires: Paidós.

Halperin Donghi, T. (1980). Proyecto y construcción de una nación (Argentina 1846-1880). Caracas: Biblioteca de Ayacucho.

Heras, C. (1954). Un agitado proceso electoral en Buenos Aires. Trabajos y comunicaciones, 4, 69-109.

Irurozqui, M. (2015). El corazón constitucional del guerrero. Ciudadanía armada y poder social en Bolivia, 1839-1875. En A. Reguera y E. C. Deckmann Fleck (orgs.). Uma história social e cultural do Direito, da Justiça e da Politica. Do antigo regime ibero-americano à contemporaneidade latino-americana (pp. 195-233). São Leopoldo: Oikos/ Editora Unisinos.

Lanteri, S. (2011). Un vecindario federal. La construcción del orden rosista en la frontera sur de Buenos Aires (Azuly Tapalqué). Córdoba: Centro de Estudios Históricos.

Larsen de Raval, A. (1989). Memorias de Juan Fugl. Vida de un pionero durante 30 años en Tandil-Argentina, 1844-1875. Argentina: La autora.

Lettieri, A. (2008). La República de las instituciones. Proyecto, desarrollo y crisis del régimen político liberal en la Argentina en tiempos de la organización nacional (1852-1880). Buenos Aires: Prometeo Libros.

López Mato, O. (2005). 1874. Historia de la revolución olvidada. Buenos Aires: Ediciones Olmo.

Macías, F. (2014). Armas y politica en la Argentina. Tucumán, siglo XIX. Madrid: CSIC.

— y Sabato, H. (2013). La Guardia Nacional: Estado, política y uso de la fuerza en la Argentina de la segunda mitad del siglo xIx. PolHis, 6 (11), 70-81. Disponible en: http://historiapolitica.com/datos/boletin/Polhis11_MACIASSABATO.pdf

Malamud, C. (2000). The origins of revolution in nineteenth-century argentina. En R. Earle (ed.). Rumours of wars. Civil conflict in nineteenth-century Latin America (pp. 29-48). Londres: ILAS. 
- (2007). ¿Cuán nueva es la nueva historia política latinoamericana? En G. Palacios (coord.). Ensayos sobre la nueva historia politica de América Latina, siglo XIX (pp. 19-30). México: El Colegio de México.

Mata de López, S. (2000). Tierra y poder en Salta. El noroeste argentino en vísperas de la independencia. Sevilla: Diputación de Sevilla.

- (2008). Paisanaje, insurrección y guerra de independencia. El conflicto social en Salta 1814-1821. En R. Fradkin y J. Gelman (comps.). Desafíos al orden. Política y sociedades rurales durante la Revolución de Independencia (pp. 61-82). Rosario: Prohistoria Ediciones.

Míguez, E. (2003). Guerra y orden social en los orígenes de la Nación Argentina, 1810-1880. Anuario IEHS, (18), 17-38.

- (2010). La frontera sur de Buenos Aires y la consolidación del Estado liberal, 18521880. En B. Bragoni y E. Míguez (coords.). Un nuevo orden político. Provincias y Estado Nacional, 1852-1880 (pp. 79-97). Buenos Aires: Biblos.

- (2011). Mitre montonero. La Revolución de 1874 y las formas de la política en la organización nacional. Buenos Aires: Sudamericana.

Oszlak, O. (2009) [1982]. La formación del Estado argentino. Orden, progreso y organización nacional. Buenos Aires: Emecé.

Paz, G. (2005). Liderazgos étnicos, caudillismo y resistencia campesina en el norte argentino a mediados del siglo XIX. En N. Goldman y R. Salvatore (2005). Caudillismos rioplatenses. Nuevas miradas a un viejo problema (pp. 319-346). Buenos Aires: Eudeba.

Pro Ruiz, J. (2012). Guerra y Estado en tiempos de construcción nacional: comentarios sobre América Latina en el siglo XIx. En J. C. Garavaglia, J. Pro Ruiz y E. Zimmermann (eds.). Las fuerzas de guerra en la construcción del Estado. América Latina, siglo XIX (pp. 17-32). Rosario: Prohistoria Ediciones/SBLA-Universitat Pompeu Fabra.

Reguera, A. (2003). Formar y transmitir el patrimonio en la pampa bonaerense del siglo XIX. El caso de Hipólito Piñero: vicisitudes de una familia para continuar. Anuario del Centro de Estudios Históricos, 3, 17-40.

Rock, D. (2006). La construcción del Estado y los movimientos politicos en la Argentina, 18601916. Buenos Aires: Prometeo Libros.

Romeo, S. (1934). Machado en el Sur. Tres Arroyos: Artes Gráficas Fernando Miralles.

Rosa, J. M. (1977). Historia Argentina. Tomo VIII. Buenos Aires: Oriente.

Ruiz Moreno, I. (2008). Campañas militares argentinas. La politica y la guerra. Guerra exterior y luchas internas (1865-1874). Buenos Aires: Claridad.

Sabato, H. (1998). La politica en las calles. Entre el voto y la movilización. Buenos Aires, 18621880. Buenos Aires: Sudamericana.

- (2002). El ciudadano en armas: violencia política en Buenos Aires (1852-1890). Entrepasados, 23, 149-169.

- (2007). La política argentina en el siglo XIX: notas sobre una historia renovada. En G. Palacios (coord.). Ensayos sobre la nueva historia política de América Latina, s. XIX (pp. 83-94). México: El Colegio de México.

- (2008). Buenos Aires en armas. La revolución de 1880. Buenos Aires: Siglo XxI Editores.

— (2012). Historia de la Argentina, 1852-1890. Buenos Aires: Siglo Xxi Editores. 
Saldías, A. (1910). Un siglo de instituciones. Buenos Aires en el Centenario de la Revolución de Mayo. Tomo II. La Plata: Taller de Impresiones Oficiales.

Schmit, R. (2004). Ruina y resurrección en tiempos de guerra. Sociedad, economía y poder en el oriente entrerriano posrevolucionario, 1810-1852. Buenos Aires: Prometeo Libros.

- (comp.). (2015). Caudillos, política e instituciones en los orígenes de la Nación Argentina. Los Polvorines: Universidad Nacional de General Sarmiento.

Tilly, C. (1992). Coerción, capital y los Estados europeos, 990-1990. Madrid: Alianza Editorial.

Yangilevich, M. (2006). José Benito Machado. Construir poder en la frontera. En R. Mandrini (ed.). Vivir entre dos mundos. Las fronteras del sur de la Argentina. Siglos XVIII y XIX (pp. 195-226). Buenos Aires: Taurus. 